\title{
EXPOSITIONS D'CEUFS DE TRUITE COMMUNE (SALMO TRUTTA) \\ À DES HYPOXIES TEMPORAIRES OU CONTINUE : EFFETS SUR LA BRANCHIE, LA RÉSORPTION DE LA VÉSICULE VITELLINE ET LES CARACTÉRISTIQUES MORPHOMÉTRIQUES DES ALEVINS.
}

\author{
F. MASSA (1), C. DELORME (2), J.L. BAGLINIERE (2), P. PRUNET (3) \\ et C. GRIMALDI (1)
}

(1) INRA, Unité Sol et Agronomie de Rennes-Quimper, 65, rue de St Brieuc, 35042 Rennes cedex, France.

(2) INRA, Laboratoire d'Ecologie Aquatique, 65, rue de St Brieuc, 35042 Rennes cedex, France.

(3) INRA, Station Commune de Recherches en Ichtyophysiologie, Biodiversité et Environnement, Campus de Beaulieu, 35042 Rennes cedex, France.

Reçu le 16 août 1999

Accepté le 30 septembre 1999
Received 16 August, 1999

Accepted 30 September, 1999

\section{RÉSUMÉ}

Des études menées en rivière sur l'oxygénation dans les frayères à salmonidés ont suggéré que la survie des embryons pendant la phase sous graviers dépend de la teneur en oxygène dans les frayères à certains moments clés du développement. Deux expérimentations ont ainsi été mises en place afin de tester les effets d'hypoxies de $3 \mathrm{mg} / \mathrm{l}$ appliquées de façon temporaire ( 7 jours) ou en continu sur le développement d'embryons de truite commune (Salmo trutta). Les effets ont été analysés en terme de survie, croissance et résorption de la vésicule vitelline, dynamique d'éclosion et mise en place de l'appareil branchial après l'éclosion en hypoxie continue et à saturation.

Les résultats ont montré que la teneur en oxygène de $3 \mathrm{mg} / \mathrm{l}$ à un débit de circulation de l'eau de $300 \mathrm{ml} / \mathrm{min}$ n'est pas létale pour les embryons, mais qu'elle induit des effets sublétaux à partir de la $3^{\text {ème }}$ semaine de développement : les dates d'éclosion sont retardées, la longueur à la fourche des alevins est significativement réduite ainsi que le poids et la teneur en eau et le taux de conversion de la vésicule vitelline. Lorsque l'hypoxie est continue, ces effets sont plus accentués et entraînent des mortalités plus élevées après l'éclosion et significativement supérieures à la résorption de la vésicule vitelline par rapport au lot témoin. Elles sont vraisemblablement dues à une limitation des échanges gazeux respiratoires liée au faible développement de l'appareil branchial sous hypoxie continue.

Mots-clés : survie, salmonidés, oxygène, branchie. 


\title{
EARLY LIFE DEVELOPMENT OF BROWN TROUT (SALMO TRUTTA) EGGS UNDER TEMPORARY OR CONTINUOUS HYPOXIAL STRESS : EFFECTS ON THE GILLS, YOLK SAC RESORPTION AND MORPHOMETRIC PARAMETERS.
}

\begin{abstract}
Ecological studies on oxygenation in redds in salmonid streams suggest that the egg-to-fry survival strongly depends on oxygen supply at key stages of development. This probably results in an increased eggs mortality. Thus two experiments have been carried out to test the effects of temporary or continuous hypoxial stress on early life development of brown trout (Salmo trutta) eggs. Survival, growth, hatching and yolk-sac resorption dynamics were analysed as well as branchial development after hatching in oxygenated and deoxygenated $(3 \mathrm{mg} / \mathrm{l}$ at a $300 \mathrm{ml} / \mathrm{min}$ water flow) conditions.
\end{abstract}

The results show that this oxygen concentration is not lethal for the embryos at hatching. However sublethal effects are observed when hypoxial stress is applied three weeks after fertilisation : hatching time is delayed, alevins are shorter, water content and yolk-sac conversion rate are lower than the ones from the control. More pronounced effects are observed under continuous hypoxic condition and higher mortalities are counted after hatching and until yolk sac resorption. This is probably due to limited respiratory exchanges linked to a reduced development of the gills.

Key-words : survival, salmonid, oxygen, gill.

\section{INTRODUCTION}

Le devenir des œufs de salmonidés enfouis sous les graviers est fortement dépendant des conditions à leur proximité immédiate (CHAPMAN, 1988). La perméabilité des graviers et le renouvellement de l'eau dans la poche d'œufs sont des paramètres de survie essentiels puisqu'ils conditionnent l'oxygénation correcte des embryons lors de leur développement (VAUX, 1962 ; BESCHTA et JACKSON, 1979 ; HENDRICKS et WHITE, 1991) et permettent l'évacuation des déchets azotés issus du métabolisme. Plusieurs études en milieu naturel (PAUWELS et HAINES, 1994 ; RUBIN, 1995 ; PETERSON et QUINN, 1996 ; MASSA et al., 1998) ou en conditions contrôlées (bief, MARTY et al., 1986) ont mesuré les teneurs en oxygène à proximité des œufs. Elles montrent une évolution des concentrations variables dans le temps et l'espace, pouvant atteindre de très faibles taux. Ces teneurs sont vraisemblablement létales pour les œufs mais la mesure des teneurs en oxygène dans la frayère n'a jamais été réalisée en continu et le suivi hebdomadaire mené dans les travaux les plus récents n'est pas réalisé avec le décompte simultané de la survie dans la frayère. De plus, une étude récente menée sur un petit bassin bas-normand à l'aide d'une sonde enregistreuse d'oxygène en continu montre une chute brutale de plusieurs $\mathrm{mg} / \mathrm{l}$ de la teneur en oxygène dans le fond du ruisseau pendant les crues (MASSA, données non publiées). Quelques mesures de la concentration en oxygène réalisées au cours de l'incubation ne reflètent donc pas les conditions dans lesquelles les embryons se sont développés et si la variabilité de ce paramètre dans le milieu est vraisemblablement influencée par la quantité de particules déposée entre les graviers, le mécanisme précis de mortalité n'a jamais été identifié (PETERSON et QUINN, 1996). II est donc aujourd'hui difficile de déterminer a posteriori le stade critique de sensibilité des œufs. 
Aucune étude à ce jour n'a été réalisée sur la sensibilité de la truite commune (Salmo trutta) à la teneur en oxygène au cours du développement embryo-larvaire. De plus, mis à part MASON (1969) sur le saumon coho (Oncorhyncus kisutch), les travaux déjà réalisés en conditions contrôlées ne décrivent pas les effets sublétaux possibles lors d'hypoxies temporaires (WICKETT, 1954 ; ALDERDICE et al., 1958 ; GARSIDE, 1966 ; HAMOR et GARSIDE, 1976 et 1977).

L'objectif de cette étude est de tester expérimentalement les effets d'une faible concentration en oxygène dissous appliquée temporairement ou en continu afin de mettre en évidence des phases de sensibilité différentes de l'embryon de truite commune au cours du développement. La teneur en oxygène retenue est la valeur minimale mesurée dans des frayères artificielles où la survie embryo-larvaire constatée a été très faible (ruisseau pépinière à lit caillouteux, MASSA et al., 1998). Deux expériences ont été mises en place pour déterminer l'impact d'hypoxies temporaires ou continues appliquées au cours du développement entre la fécondation et la résorption de la vésicule vitelline. Les effets de ces facteurs ont été analysés en terme de mortalité, cinétique d'éclosion, morphométrie à l'éclosion et à la résorption de la vésicule vitelline. De plus, les branchies des alevins sous hypoxie continue et en conditions saturées ont été observées en microscopie électronique à balayage 8 jours après l'éclosion.

\section{MATÉRIEL ET MÉTHODES}

\section{Protocole d'étude}

$j^{\text {ère }}$ expérience : de la fécondation à l'éclosion

La première expérimentation a débuté le 17 novembre 1997 et s'est terminée le 7 janvier 1998, à la fin de l'éclosion. La durée de l'expérimentation a été fixée à 6 semaines car l'éclosion des cufs à une température d'incubation de $10^{\circ} \mathrm{C}$ se produit approximativement 420 degrés jours après la fécondation. L'expérience a été divisée en 6 périodes égales d'une durée d'une semaine, soit 70 à 80 degrés jours, correspondant à la durée d'exposition à l'hypoxie (Figure 1). Chaque série est composée de 3 incubateurs de 120 œufs pour ceux soumis à une hypoxie temporaire, de 160 pour ceux du témoin en eau saturée en oxygène dissous. Un incubateur de 300 œufs représente la série sous hypoxie continue. Juste en début d'éclosion, un incubateur de la série témoin a été transféré d'une eau saturée en oxygène dissous à une eau désoxygénée, afin d'observer les effets d'une faible teneur en oxygène dissous sur les embryons prêts à éclore.

\section{$2^{\text {ème }}$ expérience : de la fécondation à la résorption de la vésicule vitelline}

La deuxième expérimentation a commencé le 16 janvier 1998 et a été menée jusqu'au 06 avril 1998, soit de la fécondation à la résorption de la vésicule vitelline (740 degrés jour). Le même type de protocole a été utilisé mais sur deux séries : hypoxie continue et témoin en conditions saturées, de la fécondation à l'émergence. Trois réplicats de 200 œufs ont été mis en place pour chaque traitement. 


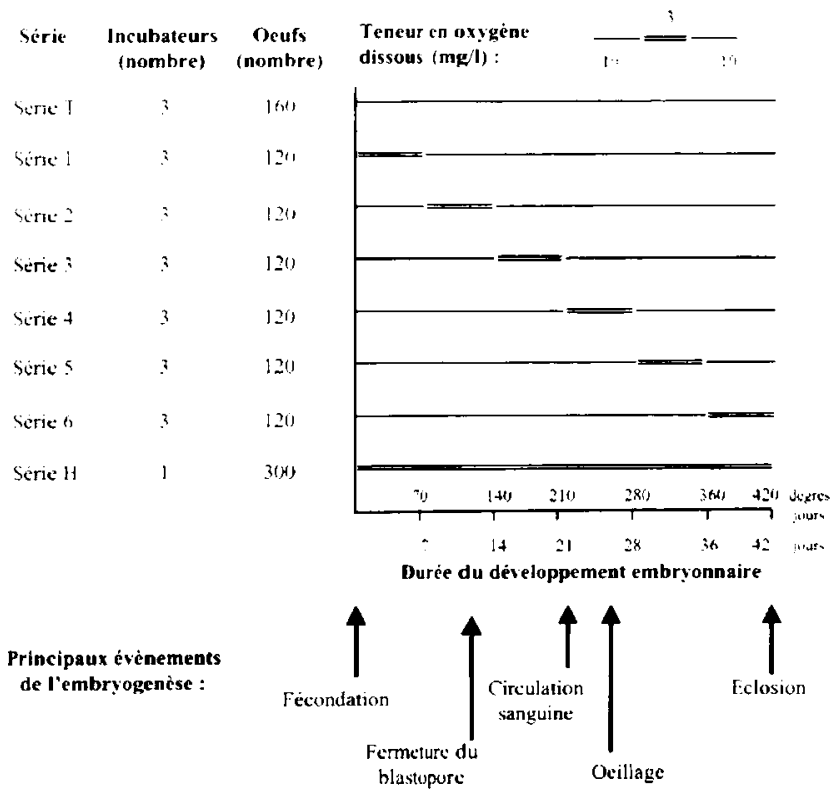

Figure 1

Protocole expérimental d'étude du développement embryonnaire des œufs exposés à des périodes d'hypoxie de $3 \mathrm{mg} / \mathrm{ll}$, temporaires (Séries 1 à 6) ou continue (Série $H$ ). Les séries sont numérotées de 1 à 6 en fonction de la semaine de développement sous hypoxie. Le témoin (Série T) correspond à une eau saturée en oxygène dissous.

Figure 1

Experimental conditions of early life development during temporary or continuous periods of hypoxial stress $(3 \mathrm{mg} / \mathrm{l})$. Numbers from 1 to 6 represents weeks of development under hypoxial stress, $\mathrm{H}$, continuous hypoxial stress and T, control.
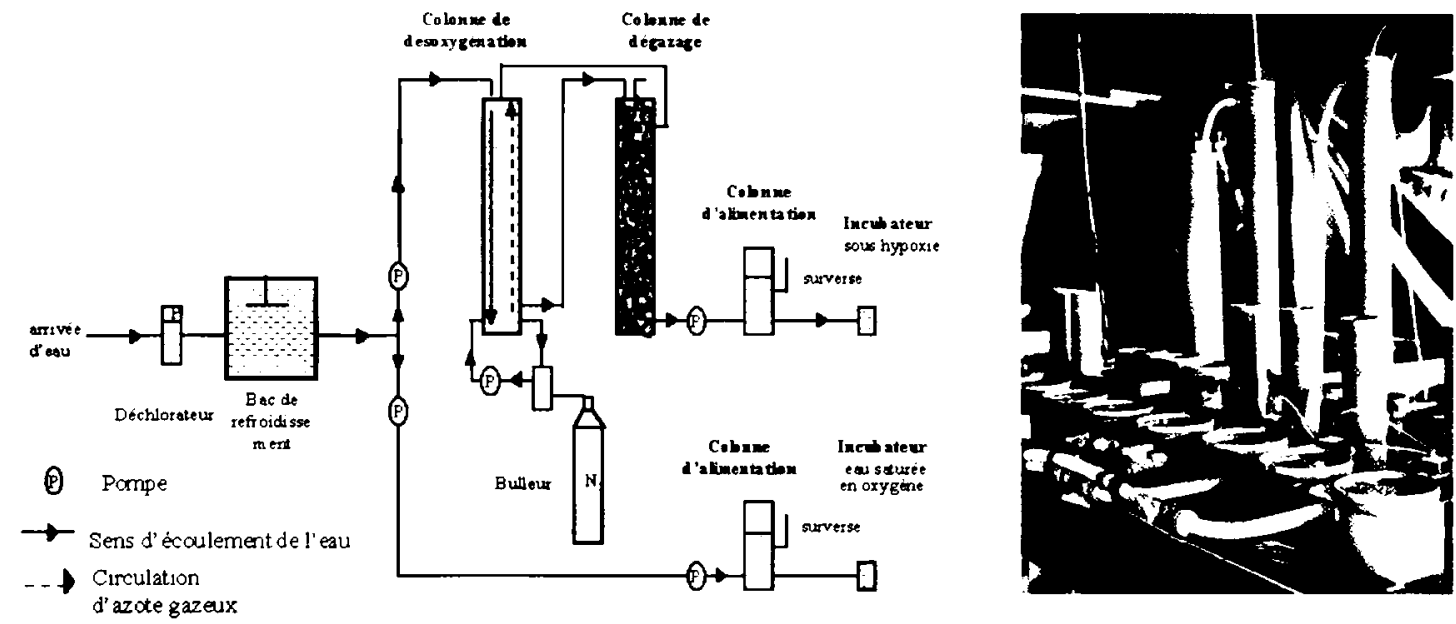

b

Figure 2

Dispositif expérimental d'alimentation des incubateurs en eau saturée en oxygène dissous et en eau partiellement désoxygénée.

Figure 2

Experimental design of water circulation in the two types of treatments (oxygenated and deoxygenated water) used in this study. 


\section{Dispositif expérimental}

\section{Dispositif général}

Le dispositif expérimental mis en place (Figures $2 a$ et $2 b$ ) a été adapté de celui utilisé par MILLER (1992). It s'agit d'alimenter des incubateurs contenant les œufs grâce à un flux d'eau de débit constant. L'eau utilisée provient du réseau d'eau potable de la commune de Rennes dont les caractéristiques physico-chimiques sont regroupées dans le Tableau la. Elle circule d'abord dans un déchlorateur, puis est stockée dans une cuve de refroidissement de 100 litres. Elle y est maintenue à une température maximale de $10^{\circ} \mathrm{C}$, et à saturation en oxygène dissous (environ $11 \mathrm{mg} / \mathrm{l}$ ). Elle est ensuite dirigée dans deux circuits distincts à l'aide de pompes électriques. Dans le premier, l'eau ne subit aucun traitement de désoxygénation. Dans le second, la concentration en oxygène dissous est abaissée à $3 \mathrm{mg} / \mathrm{l}$, selon le principe expliqué ci-après. Pour chaque circuit, une colonne d'alimentation (hauteur : $50 \mathrm{~cm}$, diamètre : $15,5 \mathrm{~cm}$, hauteur d'eau : $26 \mathrm{~cm}$ ) distribue l'eau uniformément dans les incubateurs via des tuyaux individuels, à un débit de $300 \mathrm{ml} / \mathrm{min}$. La colonne d'eau saturée est donc constamment reliée à 18 incubateurs, celle en eau désoxygénée à 4 incubateurs.

\section{Tableau I}

Composition chimique de l'eau pour les expériences I et II.

\section{Table I}

Chemical water characteristics during the experiments I and II.

a

\begin{tabular}{lc}
\hline Concentrations en ions $(\mathrm{mg} / \mathrm{l})$ & \\
\hline $\mathrm{Ca}^{2+}$ & 45,5 \\
$\mathrm{Mg}^{2+}$ & 7,5 \\
$\mathrm{~K}^{+}$ & 9,7 \\
$\mathrm{Na}^{+}$ & 21,5 \\
$\mathrm{SO}_{4}{ }^{2-}$ & 62,2 \\
$\mathrm{NO}^{-}$ & 34,4 \\
$\mathrm{Cl}^{-}$ & 48,6 \\
\hline Autres paramètres \\
\hline pH \\
Conductivité $(\mu \mathrm{S} / \mathrm{cm})$ & 7,9 \\
Température $\left({ }^{\circ} \mathrm{C}\right)$ & 467 \\
\hline
\end{tabular}

b

\begin{tabular}{ccc}
\hline $\begin{array}{c}\text { Oxygène } \\
\text { dissous }\end{array}$ & $\begin{array}{c}\text { Traitement sous } \\
\text { hypoxie }\end{array}$ & $\begin{array}{c}\text { Traitement à saturation } \\
\text { en oxygène }\end{array}$ \\
\hline mg/l & $3,4 \pm 0,4$ & $10,8 \pm 0,2$ \\
Saturation (\%) & $29,6 \pm 5,3$ & $93,8 \pm 3,3$ \\
\hline
\end{tabular}

\section{Désoxygénation de l'eau}

La désoxygénation est réalisée par passage de l'eau successivement dans deux colonnes. La première colonne (hauteur : $144 \mathrm{~cm}$, diamètre : $12,5 \mathrm{~cm}$ ) permet une désoxygénation partielle par courant inverse d'eau et d'azote gazeux. L'azote gazeux est délivré en bas de colonne à raison de $0,36 \mathrm{l} / \mathrm{min}$. La surface d'échange eau/azote gazeux est de plus augmentée par une circulation continue d'eau pompée et réinjectée en bas de la colonne. La seconde colonne (hauteur : $120 \mathrm{~cm}$, diamètre : $16 \mathrm{~cm}$ ), remplie de billes d'argile et sous atmosphère azotée, a un rôle de dégazage. La grande surface d'échange eau/azote gazeux créée par le ruissellement aléatoire de l'eau entre les billes d'argile, et le faible débit d'entrée d'eau $(1 \mathrm{l} / \mathrm{min})$ permettent d'abaisser la teneur en oxygène dissous à $3,4 \pm 0,4 \mathrm{mg} / \mathrm{l}$. L'azote gazeux en excès est transféré de la première à la seconde colonne par un tuyau en PVC puis évacué par un évent. 
Description des incubateurs

Les incubateurs ont été réalisés à partir de cylindres de plastique PVC rigide (hauteur : $13 \mathrm{~cm}$, diamètre : $16 \mathrm{~cm}$ ). Dans chaque incubateur, un grillage de plastique rigide sert de support aux œufs et est placé à mi-hauteur. Les incubateurs sont fermés par un couvercle en PVC opaque. L'eau pénètre dans chaque incubateur par la base, le trop-plein se déversant par une encoche taillée dans le couvercle. L'eau déversée par surverse des deux colonnes d'alimentations et des incubateurs est canalisée et dirigée vers la cuve de refroidissement et recyclée.

\section{Origine du matériel biologique}

Les œufs de truite ont été fécondés à la Salmoniculture Expérimentale Marine IFREMER-INRA du Drennec (Finistère) environ six heures avant leur introduction. Les stocks d'œufs provenaient de 10 femelles de 3 ans fécondées par 3 mâles de 3 ans pour la première expérience et de 8 femelles de 2 ans fécondées par 3 mâles de 3 ans pour la seconde. Les œufs fécondés ont été regroupés puis introduits dans les incubateurs. Un lot témoin pour chaque femelle a été conservé pour la première expérience. Les survies déterminées à l'éclosion étaient supérieures à $90 \%$ pour chaque lot.

\section{Suivi de l'expérimentation}

\section{Paramètres chimiques}

Les teneurs en oxygène dissous et la température de l'eau ont été contrôlées quotidiennement à l'aide d'un oxymètre (type WTW, Oxy 320) calibré avant chaque utilisation. Un test de Wrinckler a aussi été effectué au cours des expérimentations pour vérifier la validité des mesures. La saturation de l'eau pour tous les gaz et pour l'azote a été contrôlée à l'aide d'un saturomètre (Novatech, modèle $300 \mathrm{C}$ ) préalablement à l'introduction des œufs. Les valeurs moyennes de température et d'oxygène par lot expérimental sont regroupées dans le Tableau Ib.

\section{Estimation des taux de mortalité}

Un dénombrement quotidien des mortalités (blanchissement) est réalisé à heure fixe, dans chaque incubateur. La mortalité retenue est la moyenne des mortalités observée quotidiennement dans les trois incubateurs d'une même série.

\section{Cinétique d'éclosion}

La cinétique d'éclosion est décrite pour chaque incubateur par la date de première éclosion (nombre de degrés jours entre la fécondation et la première observation d'alevins éclos), la date à $50 \%$ d'éclosion (nombre de degrés jours entre la fécondation et $50 \%$ d'éclosion), et la durée de l'éclosion (nombre de degrés jours entre la première et la dernière éclosion). Le taux d'éclosion est le rapport entre le nombre d'alevins éclos sur le nombre total d'œufs en début d'éclosion. 
Résorption de la vésicule vitelline

La deuxième expérience menée a permis de suivre la résorption de la vésicule vitelline au cours du développement. Lorsque la résorption totale de la vésicule a été observée pour le lot témoin (sous loupe binoculaire), l'expérience a été stoppée. Les analyses morphométriques ont été réalisées à ce stade.

\section{Analyses morphométriques}

A la fin de la période d'éclosion, 20 alevins ont été prélevés aléatoirement dans chaque incubateur et anesthésiés dans une solution diluée de phénoxyéthanol. L'eau résiduelle a été enlevée par séchage sur papier filtre, les alevins ont été mesurés (pied à coulisse à $1,00 \pm 0,01 \mathrm{~mm}$ ), puis pesés (balance à 1,000 $\pm 0,001 \mathrm{~g}$ ) par groupes de 5 avant et après dissection de leur vésicule sous loupe binoculaire (poids humide). Les groupes d'alevins vésiculés et dévésiculés ont ensuite été séchés dans une étuve de $105^{\circ} \mathrm{C}$ pendant 5 jours, puis pesés (poids sec).

Pour la seconde expérience, les analyses morphométriques ont été réalisées à l'éclosion et à la résorption de la vésicule dans les mêmes conditions que celles décrites précédemment.

\section{Observation des branchies en microscopie électronique à balayage (MEB)}

L'observation a été réalisée 8 jours après le pic d'éclosion pour les alevins à saturation en oxygène et sous hypoxie continue. Les alevins entiers sont fixés pendant une heure à température ambiante et 24 heures à basse température dans une solution de glutaraldéhyde à $2 \%$ tamponnée à l'aide de cacodylate de sodium $(\mathrm{pH}=7,6)$. Les arcs branchiaux sont ensuite disséqués, rincés dans le cacodylate et déshydratés dans des bains d'acétone de concentration croissante. Ils sont séchés dans un appareil à point critique puis recouverts d'une fine couche d'or qui les rend conducteurs. Les observations ont été réalisées au CMEBA (Centre de Microscopie Electronique à Balayage et MicroAnalyses) de Rennes sur un microscope Jeol Model JSM 6301 F.

\section{Analyses statistiques}

L'effet de ces hypoxies successives a été mis en évidence par analyse de variance à un facteur (semaine). Les variables dont la distribution n'était pas normale ont été analysées par le test non paramétrique de Kruskall et Wallis. Les comparaisons multiples de moyennes ont été réalisées grâce au test de Tukey (validité à $P \leq 0,05$ ), les différences de survie ou de morphologie ont été analysées par les tests du $\chi^{2}$ ou de $t$ (validité à $P \leq 0,05)$. 


\section{RÉSULTATS}

\section{Mortalité}

$1^{\text {ere }}$ expérience

La mortalité moyenne cumulée des 3 incubateurs témoins en eau saturée en oxygène dissous est très faible en fin d'éclosion $(1,24 \%)$. Aucune des séries exposées temporairement ou continuellement à une hypoxie ne présente de mortalité cumulée en fin d'éclosion significativement supérieure à celle du témoin (ANOVA, $F_{622}=2,49 ; P=0,075$ ). La mortalité maximale en fin d'éclosion à cette concentration était de $4,5 \%$, et ce lors d'une hypoxie prolongée (Tableau II).

\section{Tableau II}

Mortalités à l'éclosion pour la première expérience après exposition des œufs à des périodes d'hypoxie de $3 \mathrm{mg} / \mathrm{l}$, temporaires (séries 1 à 6 ) ou continue (série $H$ ). Le témoin (série $T$ ) correspond à une eau saturée en oxygène dissous. Les valeurs représentent la mortalité moyenne pour les 3 réplicats de chaque traitement (en \% du nombre d'œufs à la fécondation).

\section{Table II}

Patterns of mortalities during experiment I (in percentage of the total number of eggs at fertilisation). Values are the mean mortality obtained for the 3 replicates per treatment. Numbers from 1 to 6 represents weeks of development under hypoxial stress, $H$, continuous hypoxial stress and $T$, control.

\begin{tabular}{lcc}
\hline Mortalité (\%) & $\begin{array}{c}\text { Début } \\
\text { d'éclosion }\end{array}$ & Fin d'éclosion \\
\hline Série T & $1,24(0,09)$ & $1,24(0,09)$ \\
Série 1 & $1,41(0,47)$ & $2,09(0,99)$ \\
Série 2 & $2,06(0,79)$ & $2,40(0,07)$ \\
Série 3 & $1,13(0,08)$ & $1,13(0,08)$ \\
Série 4 & $1,56(0,73)$ & $1,56(0,73)$ \\
Série 5 & $0,69(1,19)$ & $0,69(1,19)$ \\
Série 6 & $2,10(0,05)$ & $2,79(0,55)$ \\
Série H & $4,10(0,00)$ & $4,50(0,00)$ \\
\hline
\end{tabular}

\section{$2^{\text {ème }}$ expérience}

Jusqu'au début d'éclosion, la mortalité moyenne cumulée du témoin est de $21 \%$. Elle s'accroît de 9,3\% pendant l'éclosion, puis de $5 \%$ jusqu'à la résorption de la vésicule vitelline (Figure 3 ). Les séries expérimentales sous hypoxie présentent une évolution similaire des mortalités avec un premier accroissement dans les 150 premiers degrés jours, puis un second pendant et juste après l'éclosion. Quelle que soit la série expérimentale, les mortalités moyennes cumulées en début d'éclosion et en fin d'éclosion sont similaires (test de $\chi^{2}, \mathrm{P}=0,846 ; \mathrm{P}=0,524$ ) mais à partir de l'éclosion, les mortalités deviennent très différentes. Les mortalités sous hypoxie augmentent très rapidement et deviennent significativement supérieures par rapport au lot témoin dès 565 degrés jours (test de $\chi^{2}, P=0,038$ ) et jusqu'à la résorption de ce dernier (test de $\chi^{2}, P=0,002$ ). 


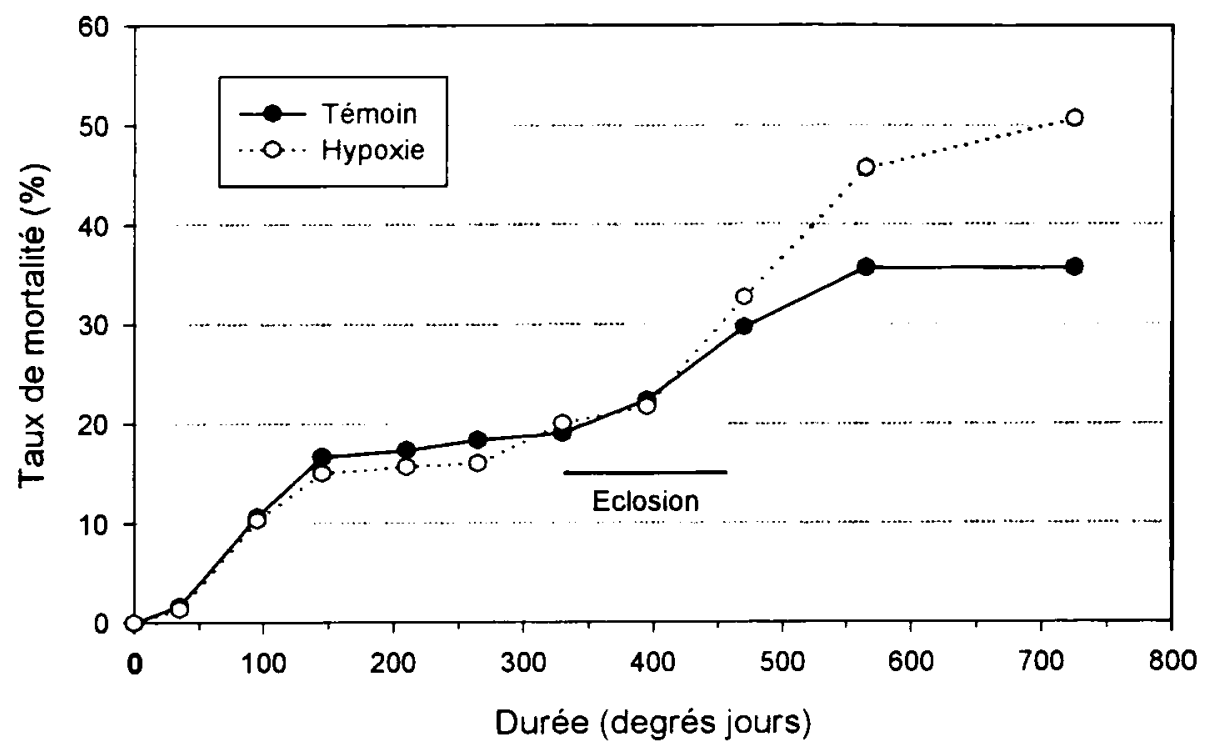

Figure 3

Mortalités moyennes cumulées des œufs puis alevins éclos en eau saturée en oxygène (Témoin) et sous hypoxie continue (Hypoxie) durant la $2^{\text {ème }}$ expérience. Les valeurs représentent la mortalité moyenne pour les trois réplicats de chaque traitement.

\section{Figure 3}

Mean temporal patterns of mortalities during experiment II. Hypoxie : reduced dissolved oxygen level, Témoin : saturated oxygen concentration. Values represent the mean of three replicates per treatment.

\section{Cinétique d'éclosion}

\section{1ere expérience}

Le taux d'éclosion moyen de la série témoin est de $100 \%$. II ne varie pas significativement lors d'une exposition temporaire ou continue en hypoxie par rapport au témoin (test de Kruskall et Wallis, $H_{7,22}=8,7 ; P=0,270$ ). L'éclosion des alevins du lot témoin débute 389 degrés jours après la fertilisation et dure 34 degrés jours. La durée de la phase d'éclosion n'est pas modifiée par une hypoxie temporaire ou prolongée $\left(F_{517}=2,22 ; P=0,119\right)$. La cinétique d'éclosion (Figure $4 a$ ) varie en fonction de la phase de développement soumise à une faible concentration en oxygène dissous. La date de première éclosion semble retardée lors des expositions temporaires à l'hypoxie mais le retard n'est significatif que pour le lot sous hypoxie prolongée (test de Tukey, $q_{8}=3,65$; $P=0,002$ ).

Les dates médianes d'éclosion sont retardées à mesure que l'hypoxie est appliquée tardivement, mais les différences ne sont significatives que lorsqu'elle survient dans les $3^{\text {ème }}, 4^{\text {ème }}$ et $5^{\text {ème }}$ semaines de développement (ANOVA, $F_{5.20}=15,80 ; P<0,001$ ) et lorsque l'hypoxie est continue (test de Tukey, $q_{8}=12,23 ; P<0,05$ ). Dans la $6^{\text {ème }}$ semaine de développement, l'hypoxie ne modifie pas la date médiane d'éclosion (test de Tukey; $P>0,05)$.

Le transfert des œufs de la série témoin à une eau désoxygénée juste avant le début de l'éclosion (fin de la $6^{\text {eme }}$ semaine) a déclenché l'éclosion de tous les alevins dans la demi-journée ( 5 degrés jours, Figure $4 b$ ). 


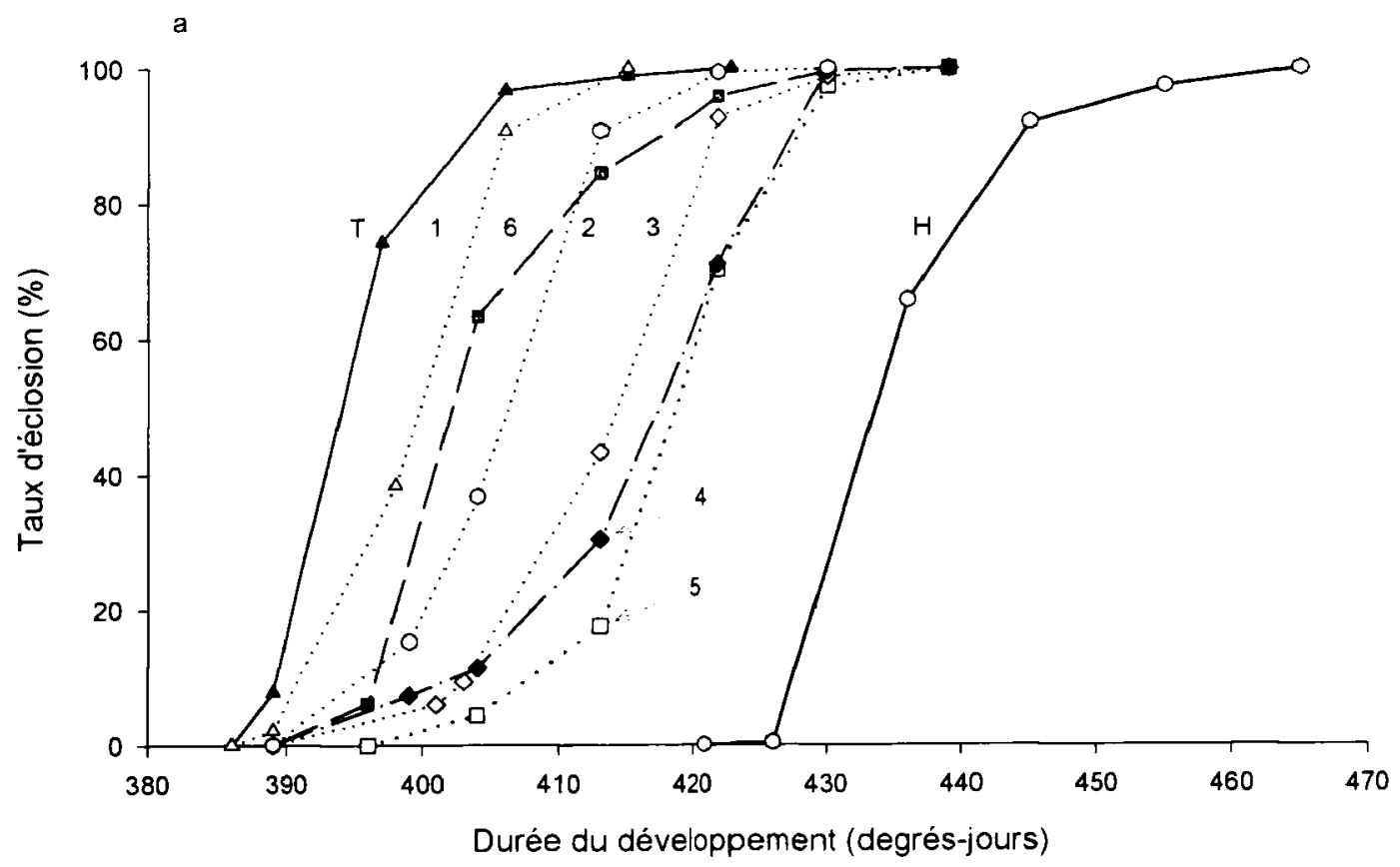

Figure 4a

Cinétique d'éclosion des œufs exposés à une hypoxie temporaire (séries 1 à 6 en fonction de la semaine de développement sous hypoxie), continue $(H)$ et du lot témoin (T).

\section{Figure 4a}

Hatching dynamics of eggs exposed to continuous $(H)$ or temporary reduced dissolved oxygen levels (numbers 1 to 6 ) and control ( $T$ ).

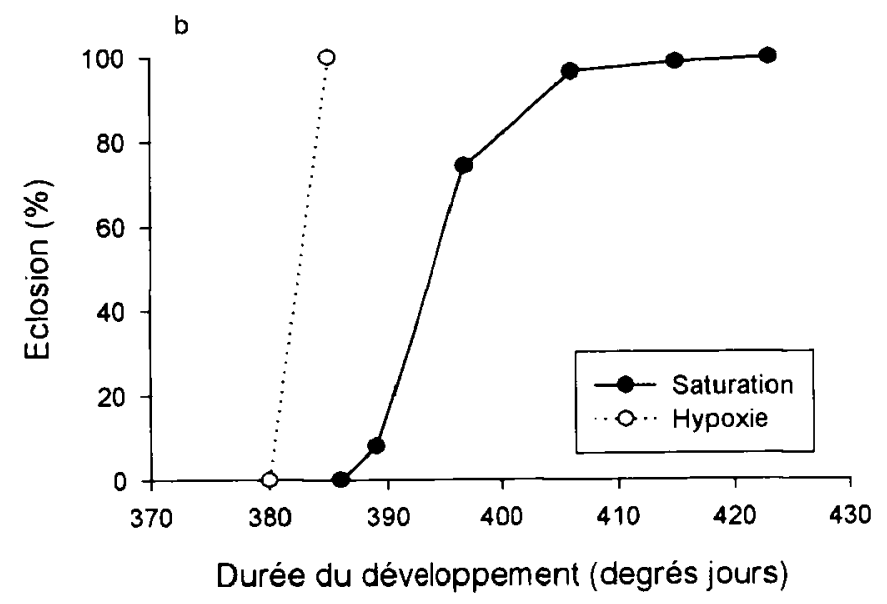

Figure 4b

Cinétique d'éclosion des œufs du lot témoin (Saturation) et induction de l'éclosion par passage en eau désoxygénée à la fin de la $6^{\text {ème }}$ semaine de développement (Hypoxie).

\section{Figure 4b}

Hatching dynamics of eggs exposed to saturated (Saturation) and reduced dissolved oxygen levels at the end of the $6^{\text {th }}$ week of development (Hypoxie). 


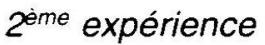

En eau saturée en oxygène dissous, l'éclosion des alevins débute 380 degrés jours en moyenne après la fécondation et dure 48 degrés jours (soit approximativement 5 jours). La durée de l'éclosion est similaire pour les deux séries expérimentales. Le taux d'éclosion est de $81 \%$ en moyenne pour les deux séries mais il est significativement retardé de 34 degrés jours sous hypoxie.

\section{Analyses morphométriques à l'éclosion}

\section{Longueur à la fourche}

\section{1 ère expérience}

La longueur à la fourche des alevins vésiculés témoins est de $17 \mathrm{~mm}$ en moyenne à l'éclosion (Figure 5a). Plus l'hypoxie temporaire est appliquée tardivement dans le développement, plus elle induit une diminution de la longueur à la fourche (test de Kruskall et Wallis, $\left.H_{7}=248,1 ; P<0,001\right)$. Cette diminution ne devient significative qu'à partir de la troisième semaine de développement (test de Tukey, $P<0,05$ ). Elle est plus marquée lorsque l'hypoxie survient en phase de pré-éclosion (test de Tukey, $q_{6}=8,86 ; P<0,05$ ) et pendant tout le développement embryonnaire (test de Tukey, $q_{7}=11,9 ; P<0,05$ ).

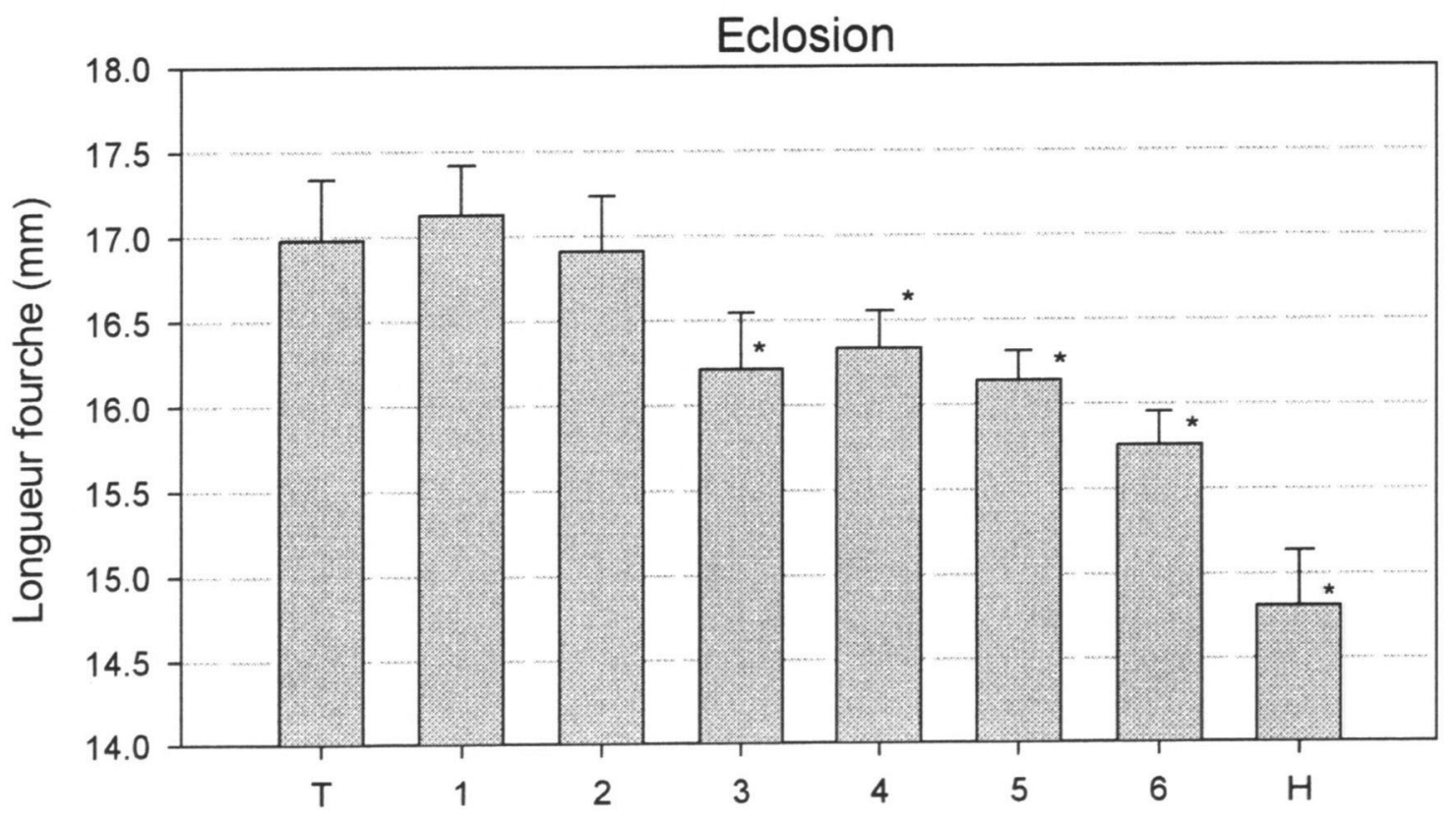

Figure 5a

Longueur à la fourche des alevins à l'éclosion (en $\mathrm{mm}$ ). La série T correspond au lot témoin en eau saturée en oxygène dissous, les séries sont numérotées de 1 à 6 selon la semaine d'exposition à l'hypoxie et $H$ est le lot sous hypoxie continue. ${ }^{*}$ significativement différent du témoin $(P<0,05)$.

\section{Figure 5a}

Fork length $(\mathrm{mm})$ of larvae at hatching. Numbers from 1 to 6 represents weeks of development under hypoxial stress, $\mathrm{H}$, continuous hypoxial stress and $\mathrm{T}$, control. * significantly different from control $(P<0,05)$. 

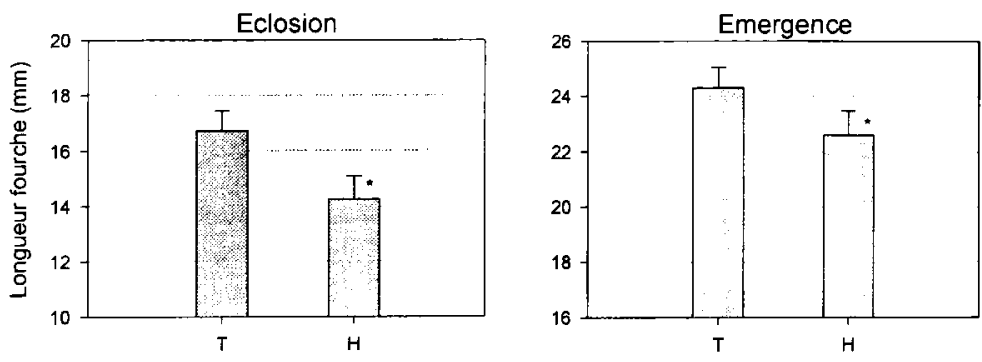

\section{Figure 5b}

Longueur à la fourche des alevins (en $\mathrm{mm}$ ) à l'éclosion et à l'émergence pour la deuxième expérimentation en eau saturée en oxygène (Témoin) et sous hypoxie continue (Hypoxie). * significativement différent du témoin $(P<0,05)$.

\section{Figure 5b}

Fork length $(\mathrm{mm})$ of larvae at hatching and control yolk sac resorption for the experiment II. Hypoxie : reduced dissolved oxygen level, Témoin : saturated oxygen concentration. ${ }^{*}$ significantly different from control $(P<0,05)$.

\section{$\underline{2^{\text {ème }} \text { expérience }}$}

A l'éclosion, la taille moyenne des alevins en eau saturée est $16,7 \mathrm{~mm}$ (Figure 5b). Elle est significativement supérieure à celle du lot sous hypoxie temporaire $(14,7 \mathrm{~mm}$; test de $t, P<0,001$ ). A 740 degrés jours (fin de résorption), la taille moyenne des alevins en eau saturée est de $24,3 \mathrm{~mm}$. Elle est significativement supérieure à celle des alevins en eau désoxygénée (test de $t, P<0,001$ ). L'écart creusé avant l'éclosion ne s'accentue pas à la résorption de la vésicule.

\section{Poids frais, teneur en eau et résorption}

\section{1 ère expérience}

A l'éclosion, le poids frais moyen total des alevins du lot témoin est de $0,087 \mathrm{~g}$ et celui de leur vésicule vitelline de $0,042 \mathrm{~g}$. Celle-ci représente $47,7 \%$ du poids frais total. $C$ poids n'est pas modifié par une hypoxie temporaire ou continue (ANOVA, $F_{7.80}=1,57$; $P=0,159)$. En revanche, celui de la vésicule vitelline a tendance à s'accroître à mesure que l'hypoxie est tardive (Figure 6a). Les différences ne sont significatives que lorsque l'hypoxie est appliquée dans les deux dernières semaines de développement (ANOVA, $F_{7.80}=21,13 ; P<0,001$ ) ou lorsqu'elle est continue (test de Tukey, $q_{8}=8,00 ; P<0,05$ ).

La teneur en eau totale des alevins du lot témoin est de $0,061 \mathrm{~g}$ et représente $69 \%$ du poids frais total. Leur corps contient $0,038 \mathrm{~g}$ d'eau en moyenne, soit $63 \%$ en moyenne de leur teneur en eau totale (Figure 7). La teneur en eau totale des alevins vésiculés diminue significativement sous hypoxie temporaire ou continue (ANOVA, $F_{748}=40,0$; $P<0,001)$ dès la deuxième semaine de développement.

La teneur en eau du corps des alevins vésiculés diminue significativement à mesure que l'hypoxie est tardive (ANOVA, $F_{7.48}=126,69 ; P<0,001$ ). Le corps des alevins sous hypoxie continue ont la teneur en eau la plus faible. Elle représente en moyenne $62 \%$ du poids pour le lot témoin et $50 \%$ sous hypoxie continue. 


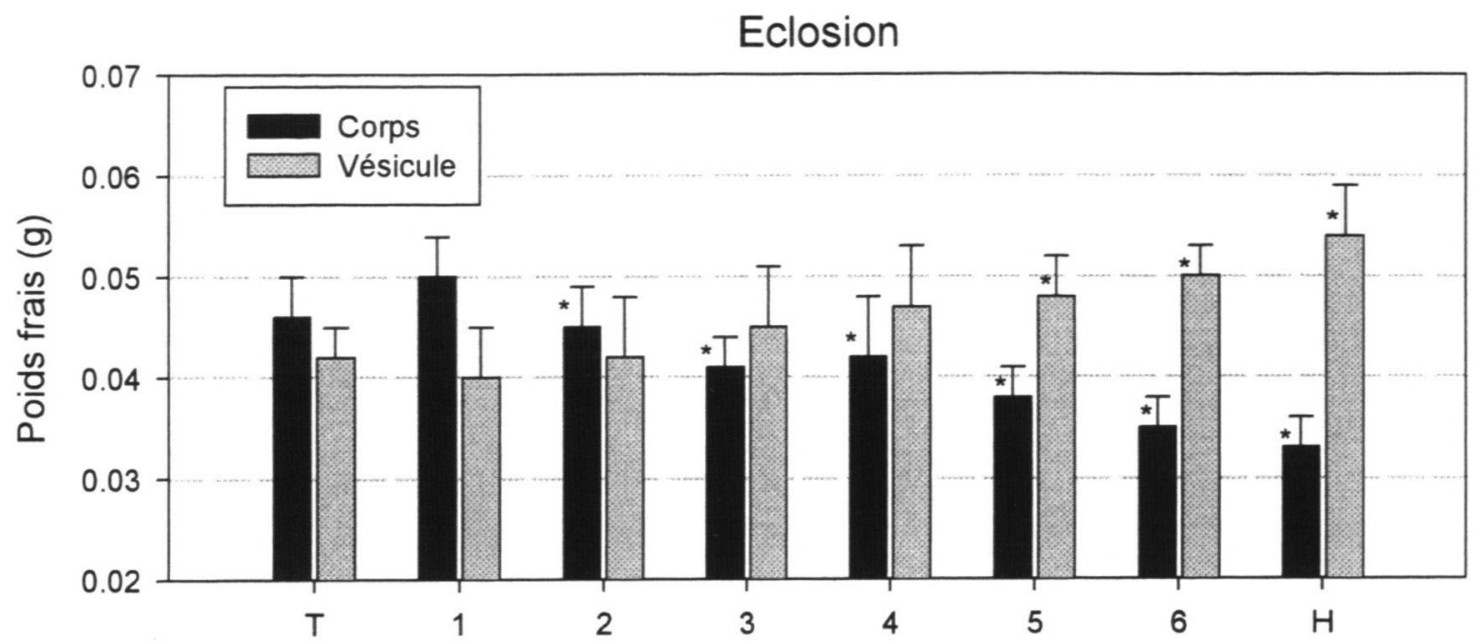

Figure 6a

Poids frais en grammes à l'éclosion du corps et de la vésicule vitelline des alevins après exposition à des périodes d'hypoxie de $3 \mathrm{mg} / \mathrm{l}$, temporaires (séries 1 à 6) ou continue (série $H$ ). Le témoin (série $T$ ) correspond à une eau saturée en oxygène dissous. * significativement différent du témoin $(P<0,05)$.

\section{Figure 6a}

Body (corps) and yolk sac (vésicule) wet weight at hatching of alevins exposed to a continuous or temporary reduced dissolved oxygen concentration. Values are in grams. Numbers from 1 to 6 represents weeks of development under hypoxial stress, $\mathrm{H}$, continuous hypoxial stress and $\mathrm{T}$, control. * significantly different from control $(P<0,05)$.
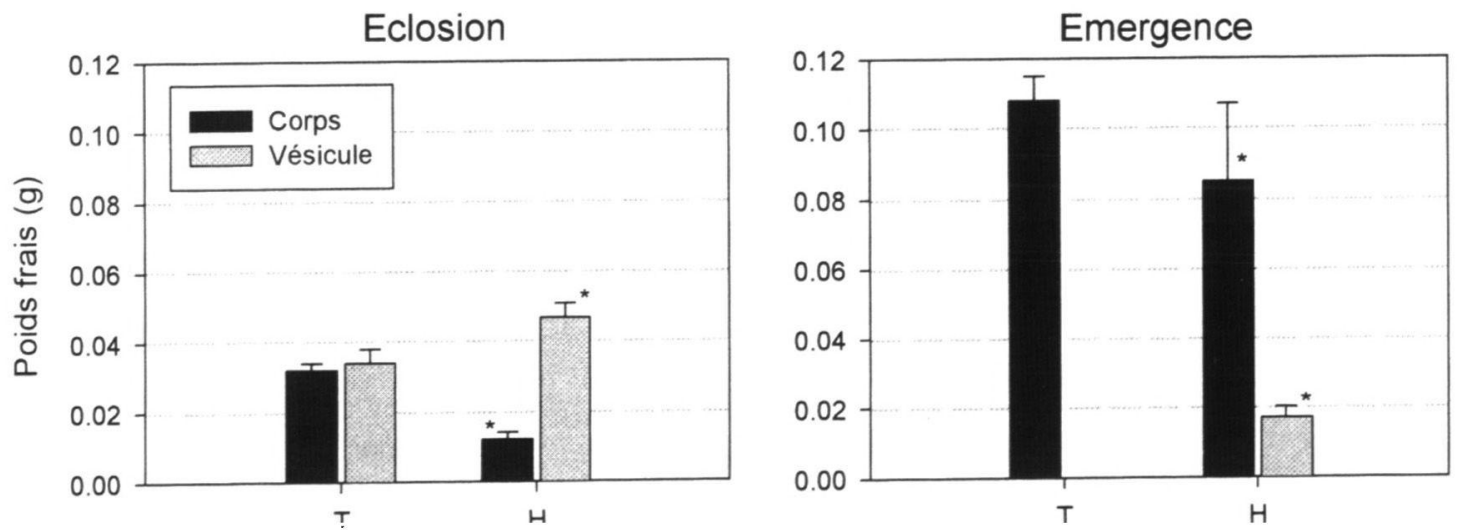

Figure 6b

Poids frais en grammes à l'éclosion et à l'émergence du corps et de la vésicule vitelline des alevins après exposition à une hypoxie continue de $3 \mathrm{mg} / \mathrm{l}(\mathrm{H})$ ou en eau saturée en oxygène dissous $(T)$. * significativement différent du témoin $(P<0,05)$.

\section{Figure 6b}

Body (corps) and yolk sac (vésicule) wet weight at hatching and yolk sac resorption of alevins exposed to a continuous reduced dissolved oxygen $(H)$ or saturated oxygen concentration $(T)$. Values are in grams. * significantly different from control $(P<0,05)$. 


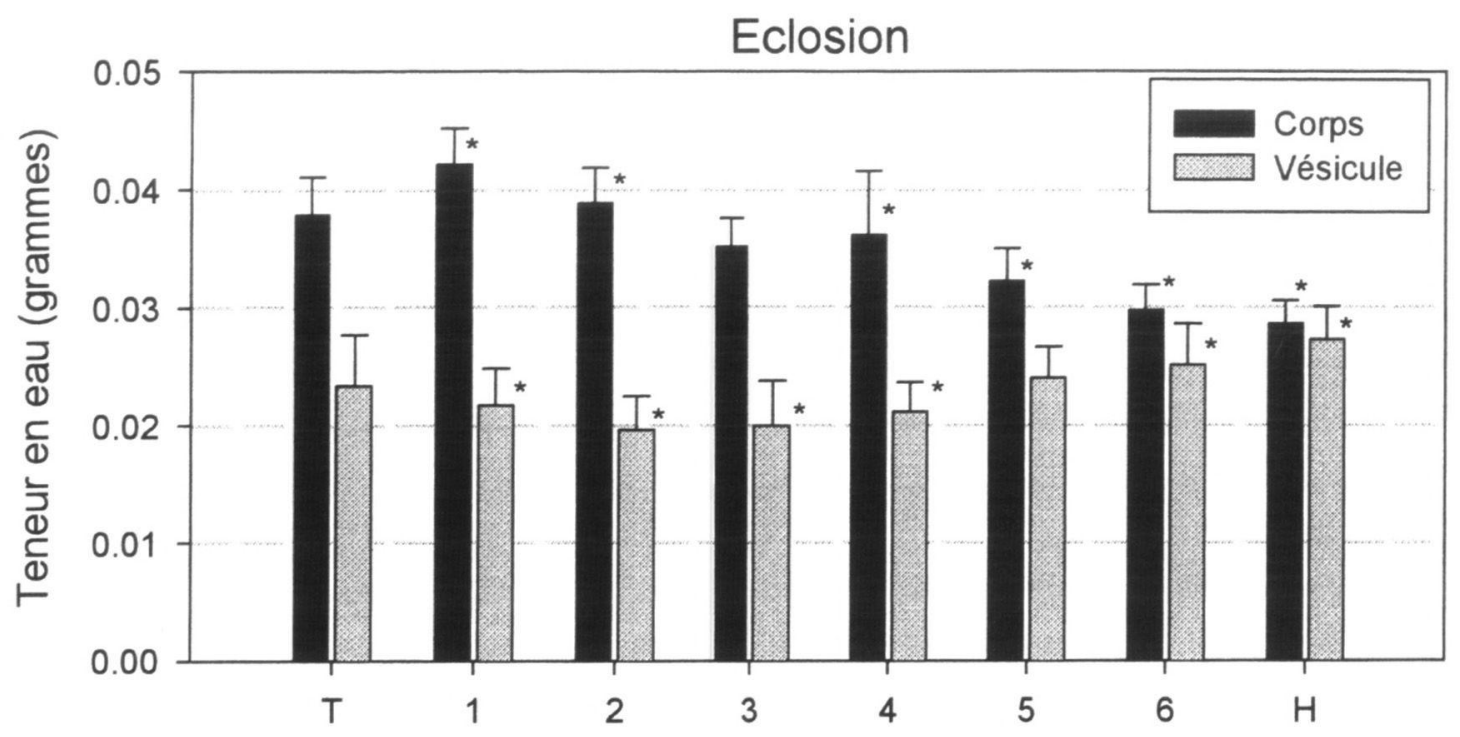

Figure 7

Teneur en eau à l'éclosion du corps et de la vésicule vitelline des alevins après exposition à des périodes d'hypoxie de $3 \mathrm{mg} / \mathrm{l}$, temporaires (séries 1 à 6 ) ou continue (série $H$ ). Le témoin (série $T$ ) correspond à une eau saturée en oxygène dissous. * significativement différent du témoin $(P<0,05)$.

Figure 7

Body (corps) and yolk sac (vésicule) water content (in \%) at hatching of alevins exposed to a continuous or temporary reduced dissolved oxygen concentration. Numbers from 1 to 6 represents weeks of development under hypoxial stress, $H$, continuous hypoxial stress and $T$, control. * significantly different from control $(P<0,05)$.

\section{$2^{\text {ème }}$ expérience}

A l'éclosion (Figure 6b), le poids frais total des alevins vésiculés en eau saturée est de $0,066 \mathrm{~g}$ en moyenne. Le poids frais moyen de leur vésicule vitelline représente $51,7 \%$ de leur poids frais total. Le poids frais total moyen des alevins sous hypoxie est significativement plus faible que celui en eau saturée (test de $t, P<0,001$ ) alors que celui de la vésicule vitelline est significativement supérieur (test de $t, P<0,001$ ).

A 740 degrés jours, la vésicule vitelline des alevins en eau saturée est entièrement résorbée tandis qu'en eau désoxygénée, la résorption est en moyenne de $65 \%$. Le poids frais total des alevins en eau saturée est de 0,108 g en moyenne, ce qui correspond au poids frais de leur corps uniquement. En revanche, les alevins encore vésiculés sous hypoxie ont un poids frais total moyen significativement plus faible que celui des alevins en eau saturée (test de $t, P<0,001$ ) et leur vésicule vitelline représente 19,6\% en moyenne de leur poids frais total.

Observations microscopiques des malformations et de la pigmentation des alevins

$\underline{1^{\text {ere }}}$ expérience

L'observation microscopique des alevins à l'éclosion n'a pas révélé de malformations corporelles. Seule la pigmentation du corps des alevins développés sous hypoxie continue est apparue plus claire que celle des autres alevins.

\section{$\underline{2}^{\text {ème }}$ expérience}

De l'éclosion à la fin de l'expérimentation, des malformations nettement visibles ont été dénombrées. Elles consistent en une cassure ou un enroulement de la queue qui ont pour la plupart, entraînés la mort des individus. Les alevins malformés sont 
significativement plus nombreux en moyenne en eau désoxygénée (test de $t, P=0,029$ ), ils représentent, $6 \%$ en eau saturée et $17 \%$ en eau désoxygénée des alevins éclos. Les alevins vésiculés sont aussi nettement moins pigmentés en eau saturée qu'en eau désoxygénée.

\section{Observations des branchies}

Le développement des arcs branchiaux 8 jours après l'éclosion pour les embryons soumis à une hypoxie continue et pour le lot contrôle au même grossissement apparaît différent. A saturation en oxygène, les lames primaires sont bien développées et l'amorce des lamelles secondaires est très visible (Figure $8 \mathrm{a}$ ). En hypoxie continue, les lames primaires sont formées mais peu allongées et les lamelles secondaires sont à peine visibles (Figure $8 b$ ). Le développement des branchies est visiblement réduit pour le lot sous hypoxie continue sachant que les alevins ont le même nombre de degrés jours.

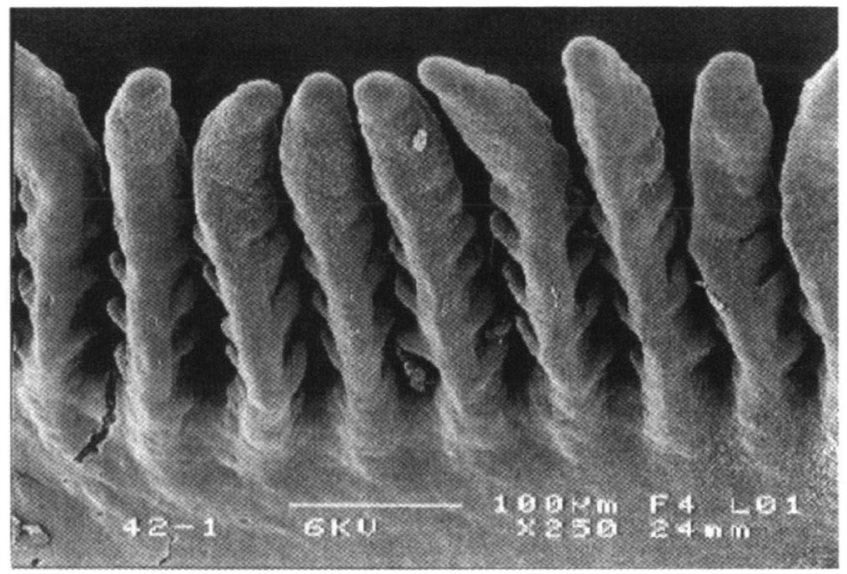

$\mathbf{a}$

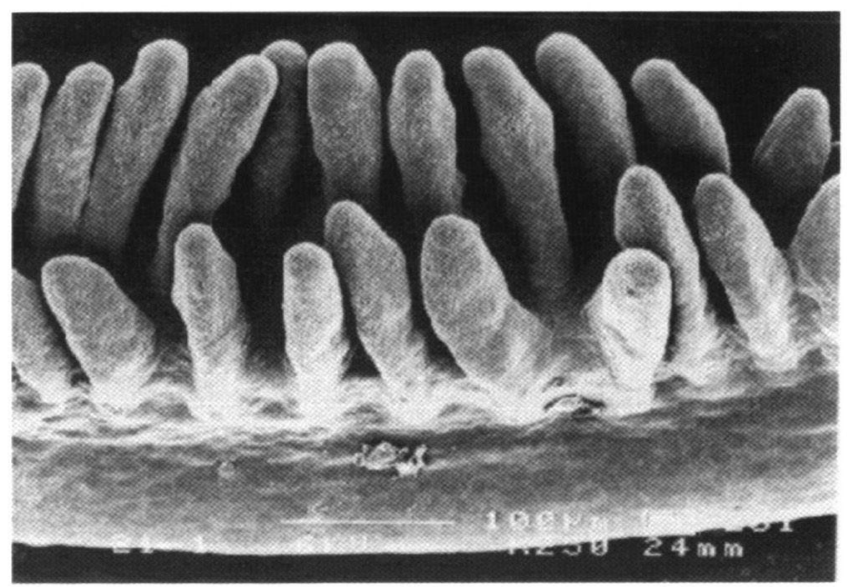

b

\section{Figure 8}

Vues en microscopie électronique à balayage d'un arc branchial à l'éclosion x 250.

a - saturation en oxygène.

b - hypoxie $(3 \mathrm{mg} / \mathrm{l})$.

\section{Figure 8}

Scanning electron microscope view of a branchial arch at hatching $\times 250$.

a - oxygen saturation.

b - hypoxial stress. 


\section{DISCUSSION}

\section{l'éclosion}

Effets d'hypoxies temporaires sur le développement entre la fécondation et

Une exposition temporaire à une teneur en oxygène dissous de $3 \mathrm{mg} / \mathrm{l}$ a entraîné un accroissement de sensibilité à la teneur en oxygène dissous au cours du développement embryonnaire. La teneur en oxygène dissous appliquée n'est en aucun cas apparue létale pour les œufs, n'influence pas le taux et la durée d'éclosion mais entraîne des effets sublétaux en terme de durée de développement et de morphologie à l'éclosion. Ils se traduisent par une diminution de la longueur à la fourche de l'alevin et une augmentation du poids de la vésicule vitelline d'autant plus marquée que l'hypoxie est appliquée tardivement. ALDERDICE et al. (1958) ont également montré l'absence de mortalité pour une teneur de 3 ppm sur le saumon chum, Oncorhynchus keta et mis en évidence que la teneur létale moyenne s'accroissait de la fécondation à l'éclosion, passant de $0,4 \mathrm{ppm}$ à 1,0-1,4 ppm. Des valeurs beaucoup plus élevées ont été reportées dans d'autres études. En effet, d'après WICKETT (1954) et DAVIS (1975), la consommation en oxygène dissous des embryons croît de la fécondation à l'éclosion et le taux d'oxygène critique (taux auquel la demande respiratoire est juste satisfaite) évolue de $1 \mathrm{ppm}$ peu après la fécondation à $7 \mathrm{ppm}$ peu avant l'éclosion. Des études ultérieures montrent que le taux d'oxygène critique ne dépend pas uniquement de la quantité dissoute dans le milieu, mais également de la vitesse de circulation de l'eau, du diamètre de l'œuf et du coefficient de diffusion au travers de la zona radiata (membrane de l'œuf) puis dans le liquide périvitellin (ROMBOUGH, 1988). Ainsi, l'impact de la concentration en oxygène reste fonction de la vitesse de circulation de l'eau et les valeurs fournies dans la littérature sont donc difficilement comparables entre elles.

Aucun effet en terme de morphologie et dynamique d'éclosion n'a été observé sur la période comprise entre la fécondation et 140 degrés jours (fin de la deuxième semaine). Le développement des œufs sous hypoxie serait peu perturbé pendant cette période car la demande en oxygène est minime et est partiellement couverte par les réserves d'oxygène dissous de la poche ovulaire, l'oxygène y étant de plus très soluble (KECKEIS et al., 1996). Si l'on prend comme référence la consommation en oxygène de l'embryon de saumon chum qui est de $4,91 \mathrm{~mm} / \mathrm{g} / \mathrm{min}$ à 122 degrés jours (ALDERDICE et al., 1958), une teneur de $3 \mathrm{mg} / \mathrm{l}$ renouvelée à un débit de $300 \mathrm{ml} / \mathrm{min}$ couvre largement les besoins de l'embryon à ce stade.

A partir de 140 degrés jours après la fécondation, les hypoxies temporaires modifient les caractéristiques morphologiques des alevins à l'éclosion. Ces modifications se traduisent par une augmentation de la proportion relative de la vésicule vitelline et inversement par une diminution de la longueur à la fourche des alevins vésiculés et de leur teneur en eau. Elles sont d'autant plus accentuées que l'exposition à l'hypoxie est tardive. A ces stades plus avancés, la réserve en oxygène dissous dans la vésicule vitelline ou la disponibilité en oxygène du milieu ne seraient plus suffisantes pour couvrir tous les besoins métaboliques. Les réserves étant prioritairement allouées aux processus de différenciation (WINNIKI, 1967), le taux de croissance serait de ce fait ralenti (HAMOR et GARSIDE, 1977). Les résultats obtenus dans cette étude apportent des données nouvelles sur les conséquences d'une hypoxie temporaire car la morphologie des alevins à l'éclosion n'avait pas été analysée dans les études d'ALDERDICE et al. (1958) et de KECKEIS et al. (1996).

L'éclosion prématurée à 380 degrés jours des œufs transférés dans une eau désoxygénée laisse supposer qu'une teneur en oxygène dissous de $3 \mathrm{mg} / \mathrm{l}$ est devenue insuffisante pour la respiration des embryons confirmant ainsi les observations de LATHAM et JUST (1988) sur l'effet stimulant d'une diminution de la pression partielle en oxygène dissous sur des embryons de truite Arc-en-ciel, Oncorhynchus mykiss, prêts à éclore. D'après ces auteurs, l'élimination de la zona radiata permettant d'augmenter la 
surface respiratoire, l'éclosion précoce serait un moyen de pallier la limitation des échanges gazeux respiratoires à l'intérieur de l'œuf. Ces éclosions pourraient être induites par un accroissement de la mobilité des œufs dans leur poche ovulaire, et par une stimulation de l'enzyme du chorion (HAMOR et GARSIDE, 1977).

\section{Effets d'une hypoxie continue sur le développement entre fécondation et résorption}

En premier lieu il semble important de préciser que la comparaison des deux expérimentations en hypoxie continue doit prendre en compte une différence vraisemblable de qualité des œufs. Ces deux expérimentations ne pouvant être menées conjointement d'un point de vue technique, les œufs incubés pour la $2^{\text {eme }}$ expérimentation sont issus de pontes tardives. Or, le taux de mortalité des œufs à leur réception (environ $10 \%$ avant leur mise en place dans les incubateurs), la différence de mortalité à l'éclosion (30,3\% contre $1,2 \%$ pour la première expérience), la réussite d'éclosion moins importante (81\% contre $100 \%$ ) ainsi que les malformations corporelles constatées sur les alevins vésiculés laissent envisager une qualité moindre des œufs. Elle pourrait s'expliquer par un phénomène de surmaturation des ovules dans la cavité abdominale des femelles (FLETT et al., 1996). Dans la seconde expérimentation, les stress prénataux d'origine maternelle se surajoutent donc vraisemblablement à celui d'une réduction de la teneur en oxygène.

Une exposition prolongée à une concentration en oxygène dissous de $3 \mathrm{mg} / \mathrm{l}$ n'a pas provoqué d'accroissement de mortalité entre la fécondation et l'éclosion mais la morphologie des alevins à l'éclosion est fortement marquée par la teneur réduite en oxygène dissous du milieu. Les alevins sont de petite taille, leur poids frais est plus faible et le taux de conversion des réserves vitellines est faible. Ces conséquences ont déjà été observées sur d'autres espèces (saumon coho, Oncorhynchus kisutch, BRANNON, 1965 ; saumon kokanee, Oncorhynchus nerka, MASON, 1969) et pour la truite commune en conditions respiratoires particulièrement défavorables (huile de paraffine et eau stagnante, WINNIKI, 1967). L'éclosion apparaît comme une phase critique du développement embryonnaire (KECKEIS et al., 1996 ; GONZALEZ et al., 1996), et pourrait traduire une accumulation de déficiences au cours de l'embryogenèse.

Après l'éclosion, la mortalité augmente fortement et est très significative à la résorption de la vésicule vitelline du lot témoin $(P=0,002)$. La taille des alevins survivants est plus faible que celle des alevins en conditions d'oxygénation optimales mais l'écart de taille observé avant l'éclosion ne s'est pas accentué à la résorption. A 740 degrés jours, la résorption incomplète de la vésicule vitelline pour les alevins en eau désoxygénée confirme le faible taux de conversion de la vésicule et le ralentissement du temps de développement déjà observés pour les hypoxies temporaires de façon moins accentuée. Théoriquement on peut calculer le temps de résorption restant pour les alevins en eau désoxygénée. Sachant qu'à 740 degrés jours, $65 \%$ de la vésicule a été résorbée, il manque alors 398 degrés jours aux alevins sous hypoxie pour épuiser leurs réserves vitellines et terminer leur développement, soit environ 40 jours à $10^{\circ} \mathrm{C}$. Ce chiffre est à rapprocher de celui déterminé expérimentalement par MASON en 1969 (168 degrés jours) dans les mêmes conditions $\left(9,5^{\circ} \mathrm{C}\right.$ et $3 \mathrm{mg} / \mathrm{l}$ en oxygène dissous). La différence observée est vraisemblablement due aux deux vitesses apparentes de l'eau appliquées $(2230 \mathrm{~mm} / \mathrm{h}$ pour MASON et $900 \mathrm{~mm} / \mathrm{h}$ dans notre expérience). La dynamique de résorption de la vésicule est un paramètre important car il représente la quantité de réserves encore non utilisée au cours de l'embryogenèse (HAMOR et GARSIDE, 1977). La réduction du taux de conversion des réserves énergétiques vitellines pendant l'embryogenèse est une réponse commune à l'hypoxie et a été démontrée pour des embryons de saumon chum (ALDERDICE et al., 1958), de saumon atlantique (HAMOR et GARSIDE, 1977) ou de nase, Chondrostoma nasus (KECKEIS et al., 1996). L'effet cumulé d'une émergence tardive et d'un déficit global de croissance déjà acquis avant l'éclosion pourraient avoir un effet important sur la survie des alevins en rivière du fait d'une baisse de compétitivité liée 
aux caractéristiques morphologiques des poissons comme le montrent les travaux de MASON (1969).

Au moment de l'éclosion, la larve se libère de sa coquille et les branchies sont en contact avec le milieu environnant. Le développement de l'appareil branchial de la truite arc-en-ciel Salmo gairdneri a été décrit par plusieurs auteurs (MORGAN, 1974a et 1974b; SHEN et LEATHERLAND, 1978 ; GONZALEZ et al., 1996) dans des conditions d'oxygénation optimales. Le même type d'observations a été réalisé récemment sur des alevins de truite commune (PISAM et al., sous presse). Elles montrent l'apparition successive des lames primaires et des lamelles secondaires au cours du développement. Ces dernières sont bien différenciées à la résorption de la vésicule vitelline mais apparaissent déjà au moment de l'éclosion. Or la fonctionnalité de la branchie en terme de respiration est liée à l'importance de la surface d'échange entre l'eau et le sang ; celui ci n'est séparé de l'eau que d'une à deux couches de cellules et les échanges gazeux se font par diffusion du milieu le plus riche vers le moins concentré (DAVIS, 1975). Le développement plus réduit des lames primaires et lamelles secondaires pour les lots sous hypoxie limite la surface d'échange respiratoire possible et permettent vraisemblablement d'expliquer une partie des mortalités observées entre l'éclosion et la résorption de la vésicule vitelline, les alevins ne pouvant compenser la faible teneur en oxygène dans leur environnement par un système branchial peu développé. Les différentes teneurs en eau observées entre les traitements pourraient aussi provenir du développement incomplet de la branchie. En effet, celle-ci est un des principaux organes régulateur de l'équilibre minéral du poisson qui devient fonctionnel autour de l'éclosion (GONZALEZ et al., 1996). Son mauvais fonctionnement pourrait entraîner à ce stade des capacités réduites de régulation provoquant cette variabilité des teneurs en eau.

\section{CONCLUSION}

Ces deux expérimentations mettent en évidence l'accroissement de sensibilité des embryons à une diminution de la concentration en oxygène dissous de la fécondation à la résorption de la vésicule vitelline. Une teneur en oxygène dissous de $3 \mathrm{mg} / \mathrm{l}$ ne représente pas une teneur létale lorsqu'elle est appliquée temporairement mais elle peut être considérée comme une teneur critique pour le développement des embryons à un débit de circulation de l'eau de $300 \mathrm{ml} / \mathrm{min}$ et ce à partir de la troisième semaine de développement. Elle se traduit par des réponses différentielles en terme de durée de développement et de morphologie des alevins à l'éclosion. De plus, les expositions continues à une hypoxie de $3 \mathrm{mg} / \mathrm{l}$ montrent que les conditions d'oxygénation des embryons avant l'éclosion sont déterminantes pour le développement des alevins, ces conséquences se répercutant sur toute la période de résorption de la vésicule.

Pour ces deux expérimentations, les résultats de morphologie des épithéliums branchiaux apportent des outils précieux pour la compréhension des données de mortalité, de morphométrie et de retard de développement analysés dans le cadre de cette étude.

\section{REMERCIEMENTS}

Les auteurs remercient chaleureusement D. Azam et P.M. Lucas pour leur collaboration technique et leur aide dans le suivi quotidien des installations. Merci également à $L$. Carteaux pour les analyses en chromatographie ionique et à J. Lelannic pour les observations en microscopie électronique à balayage.

Ce travail a été réalisé dans le cadre d'une thèse de doctorat financé par le Ministère français de la Recherche et de la Technologie. 


\section{BIBLIOGRAPHIE}

ALDERDICE D.F., WICKETT W.P., BRETT J.R., 1958. Some effects of temporary exposure to low dissolved oxygen levels on Pacific Salmon eggs. J. Fish. Res. Bd. Can., 15 (2), 229-249.

BESCHTA R.L., JACKSON W.L., 1979. The intrusion of fines sediments into a stable gravel bed. J. Fish. Res. Board Can., 36, 204-210.

BRANNON E.L., 1965. The influence of physical factors on the development and weight of sockeye salmon embryos and alevins. International Pacific Salmon Fisheries Commission Progress Report, 12, 1-25.

CHAPMAN D.W., 1988. Critical review of variables used to defined effects of fines in redds of large salmonids. Trans. Am. Fish. Soc., 117, 1-21.

DAVIS J.C., 1975. Minimal dissolved oxygen requirements of aquatic life with emphasis on Canadian species : a review. J. Fish. Res. Board Can., 32, 2295-2332.

FLETT P.A., MUNKITTRICK K.R., VAN DER KRAAK G., LEATHERLAND J.F., 1996. Overripening as the cause of low survival to hatch in Lake Erie coho salmon (Onchorhyncus kisutch) embryos. Can. J. Zool., 74, 851-857.

GARSIDE E.T., 1966. Effects of oxygen in relation to temperature on the development of embryos of brook trout and rainbow trout. J. Fish. Res. Board Can., 23, 1121-1134.

GONZALEZ M.E., BLANQUEZ M.J., ROJO C., 1996. Early gill development in the rainbow trout (Onchorhyncus mykiss). J. Morph., 229, 201-217.

HAMOR T., GARSIDE E.T., 1976. Developmental rates of embryos of Atlantic salmon Salmo salar $\mathrm{L}$. in response to various levels of temperature, dissolved oxygen and water exchange. Can. J. Zool., 54, 1912-1917.

HAMOR T., GARSIDE E.T., 1977. Size relations and yolk utilization in embryonated ova and alevins of Atlantic salmon (Salmo salar L.) in various combinations of temperature and dissolved oxygen. Can. J. Zool., 55, 1892-1898.

HENDRICKS S.P., WHITE D.S., 1991. Physicochemical patterns within a hyporheic zone of a northern Michigan river, with comments on surface water patterns. Can. J. Fish. Aquat. Sci., 48, 1645-1654.

KECKEIS H., BAUER-NEMESCHKAL E., KAMLER E., 1996. Effects of reduced oxygen level on the mortality and hatching rate of Chondrostoma nasus embryos. J. Fish Biol., 49, 430-440.

LATHAM K.E., JUST J.J., 1988. Oxygen availability provides a signal for hatching in the rainbow trout (Salmo gairdneri) embryo. Can. J. Fish. Aquat. Sci., 46, 55-58.

MARTY C., BEALL E., PAROT G., 1986. Influence de quelques paramètres du milieu d'incubation sur la survie d'alevins de saumon atlantique (Salmo salar L.) en ruisseau expérimental. Int. Rev. Ges. Hydrobiol., 71 (3), 349-361.

MASON J.C., 1969. Hypoxial stress prior to emergence and competition among coho salmon fry. J. Fish. Res. Bd. Can., 26, 63- 91.

MASSA F., GRIMALDI C., BAGLINIERE J.L., PRUNET P., 1998. Evolution des caractéristiques physico-chimiques de deux zones de frayères à sédimentation contrastée et premiers résultats de survie embryo-larvaire de truite commune (Salmo trutta). Bull. Fr. Pêche Piscic., 350/351, 359-376.

MILLER W.J., 1992. An incubation system allowing multiple dissolved oxygen and temperature combinations for salmonid emergence studies. Prog. Fish. Cult., 54, 259-263.

MORGAN M., 1974a. The development of gill arches and gill blood vessels of the rainbow trout Salmo gairdneri. J. Morph., 142, 351-364. 
MORGAN M., 1974b. Development of secondary lamellae of the gills of the trout, Salmo gairdneri (Richardson). Cell. Tiss. Res., 151, 509-523.

PAUWELS S.J., HAINES T.A., 1994. Survival, hatching and emergence success of Atlantic salmon eggs planted in three Maine streams. N. Am. J. Fish. Manag., 14, 125-130.

PISAM P., MASSA F., JAMMET C., PRUNET P. Chronology of $\beta$, A and $\alpha$ mitochondria rich cells appearance in the gill epithelium during the ontogenesis of the brown trout (Salmo trutta). The Anatomical Record, in press.

PETERSON N.P., QUINN T.P., 1996. Spatial and temporal variation of dissolved oxygen in natural egg pockets of chum salmon in Kennedy creek, Washington. J. Fish. Biol., 48, 131-143.

ROMBOUGH P.J., 1988. Respiratory gas exchange, aerobic metabolism, and effects of hypoxia during early life. In : HOAR W.S. and RANDALL D.J. (Eds.), Fish physiology, Academic Press Publ., San Diego, 123-143.

RUBIN J.F., 1995. Estimating the success of natural spawning of salmonids in streams. J. Fish Biol., 46, 603-622.

SHEN A.C.Y., LEATHERLAND J.F., 1978. Structure of the yolksac epithelium and gills in the early developmental stages of rainbow trout (Salmo gairdneri) maintained in different water salinity. Env. Biol. Fish., 3 (4), 345-354.

VAUX W.G., 1962. Interchange of stream and intragravel water in a salmon spawning riffle. United States Fish and Wildlife Service Special Scientific Report, Fisheries $N^{\circ} 405$.

WICKETT W.P., 1954. The oxygen supply to salmon eggs in spawning beds. J. Fish. Res. Bd. Can., 1116, 933-953.

WINNICKI A., 1967. Embryonic development and growth of Salmo trutta L. and Salmo gairdneri Rich. in conditions unfavourables to respiration. Zoologica Poloniae, 1745-1758. 